\title{
Sobre la tendencia prospectiva en la Temporalidad heideggeriana
}

\section{On the Forward-looking Tendency in Heideggerian Temporality}

Na tendência prospectiva na Temporalidade heideggeriana

Mauricio Suil Cerda ${ }^{1}$

Recibido: 05/08/2016 - Aceptado: 03/11/2016

\begin{abstract}
Resumen:
La siguiente reflexión se abocará a revelar el carácter del tiempo desde su dinámica extático-horizontal, atendiendo a su tendencia prospectiva en el marco de Ser y Tiempo. Se analizan los momentos de articulación extático-horizontal como un punto particularmente relevante para apreciar la marcada tendencia prospectiva del tiempo heideggeriano. Luego, emerge el problema de la tradición como fenómeno constitutivo en perspectiva, ya no de una tendencia prospectiva, sino desde un movimiento eminentemente retroproyectivo.
\end{abstract}

Palabras clave: temporariedad - temporeidad - éxtasis - esquemas horizontales - tradición

\begin{abstract}
:
The following reflection will be focused entirely on revealing the nature of time from its ecstatic-horizontal dynamics, addressing to its forwardlooking tendency in the framework of Being and Time. The moments of ecstatic-horizontal articulation are analyzed as a particularly relevant point to appreciate the marked forward-looking tendency of Heideggerian time. Then, the problem of tradition emerges as a constitutive phenomenon in perspective, not from a forward-looking tendency, but from an eminently retroprojective movement.
\end{abstract}

Keywords: temporareity - temporeity - ecstasy - horizontal schemes tradition

\footnotetext{
${ }^{1}$ Chileno. Magíster en Filosofía Contemporánea. UAH. Chile. E-mail: suiltro@hotmail. com
} 


\section{Resumo:}

A seguinte reflexão apontará revelar o caráter do tempo desde sua dinâmica extático-horizontal, atendendo sua tendência prospetiva no marco de Ser e Tempo. Analisam-se os momentos de articulação extático-horizontal como um ponto particularmente importante para apreciar a tendência prospetiva de tempo heideggeriano. Logo, surge o problema da tradição como fenômeno constitutivo em perspectiva, já não desde uma tendência prospetiva, mas a partir de um movimento eminentemente retro projetivo.

Palavras-chave: temporariedade - temporalidade - êxtases - esquemas horizontais - tradição

\section{Introducción}

Da la impresión que sólo quedan rastrojos de interés en un campo archiestudiado como lo es el heideggeriano. Por lo demás, entrar en su mundo conceptual resulta difícil sin sustraerse al típico neologismo que lo caracteriza. Cierta clase de aquella voracidad académica ha servido de contexto para el presente análisis, el cual asume su propia paradoja, arriesgando la estimación sobre su novedad y vigencia. Aunque no sea posible justificar estas aprensiones, desentrañar la esencia del tiempo sigue resultando un tema no agotado, el cual podría apreciarse particularmente en esta revisión de la dinámica prospectiva y sus posibilidades constitutivas.

Instalar la pregunta por el sentido del ser tiene un mérito singular. No quisiera referirme a rescatar la cuestión del ser desde su olvido histórico, sino más bien poner el acento en esa suerte de integración del dinamismo lineal y circular del tiempo, predominantes en la historia de la metafísica. Esto ha supuesto una direccionalidad temporal que determina, desde un transcurrir proyectivo o cíclico, la comprensión del mundo en cuanto tema general del pensamiento.

Heidegger analiza la estructura tempórea del ser en general compuesta unitariamente por una dinámica prospectiva y retrospectiva, donde la primacía estaría depositada en la primera. Esto resulta existencialmente relevante a la hora de recoger la finitud como constituyente existencial del Dasein y con ello de la historicidad del ser. Asimismo, 
la crítica destructiva de la tradición filosófica expresaría este doble movimiento ontológico del ser que se reposiciona en perspectiva de su sentido. ¿Pero no será ésta una tendencia limitante para dar con el sentido del ser en general? ¿Es que acaso la tradición no es de alguna manera eminente? ¿Hasta qué punto se manifiesta ontológicamente el pasado como una experiencia histórica básica en la estructura temporal heideggeriana? ¿Es posible imaginar una tendencia retrospectiva en la constitución del ser?

Recordemos que Ser y Tiempo da paso a una nueva dimensión de análisis ontológico radicalizando el tiempo en una doble distinción: la Temporeidad y la Temporariedad. La primera entendida como el tiempo propio que abre el sentido del Dasein, y la segunda referida al tiempo del ser en cuanto tal, el cual se alza desde un modo originario de temporización de la Temporeidad misma. La Temporariedad sería por tanto la estructura global de autogeneración de sentido que abre a cada ente en su posibilidad y articula el mundo en sus diferentes dimensiones ontológicas, operando como trasfondo desde el cual -y en un proceso de comprensión situada- aparecen los entes, dinámica que se basa en la estructura extático-horizontal de la Temporeidad, dando cuenta de la tendencia prospectiva fundamental. Si la formación de sentido es un proceso de autoformación propia del tiempo de un modo dinámico extático horizontal, evaluar la tendencia conferida por Heidegger al tiempo nos lleva a revisar la importancia de esta dinámica y su función al interior de la analítica ontológica, puesto que allí la conexión tiempo-sentido se encuentra elaborada de manera más radical (cf. Rubio 8 ).

\section{Analítica del Dasein y preeminencia anticipativa: cuidado $y$ finitud}

Debemos apuntar a la articulación del tiempo en la analítica ontológica, definida ésta como un esfuerzo preliminar por descubrir el horizonte del sentido del ser en general. El tiempo emerge paulatinamente como desvelamiento de la Temporeidad desde el análisis de aquel ente caracterizado por su temporalidad constitutiva, lo que va a exigir el 
cuestionamiento de éste en su carácter de Dasein (Heidegger 65). Por eso se habla de circularidad referencial "retrospectiva o anticipativa" (Id. 31), es decir, el movimiento en el que el Dasein, inmerso en una pre-comprensión del ser, es proyectado como totalidad temporal: comprendido en la transversalidad existencial que involucra su ser desde el 'antes' de su haber-sido y en el 'después' de su posibilidad existencial. La existencia del Dasein es desplegada extáticamente en la forma propia de su pasado que acontece desde su futuro (Id. 44). Pero esto se transparenta captando los elementos esenciales de la relación del Dasein con el mundo y la determinación fundamental de su ser como cuidado.

Si comprender al «ser en general» es comprender el «ser del Dasein» (Heidegger 35) esto es posible teniendo en cuenta la peculiaridad óntica de este último como ser ontológico. Ahora bien, la comprensión del Dasein "comporta, pues, con igual originariedad, la comprensión de algo así como un "mundo", y la comprensión del ser del ente que se hace accesible dentro del mundo" (Id. 36). De este modo, el primer dato ontológico es su existencia en-el-mundo junto a los entes intramundanos, evidenciando con ello su co-pertenencia ontológica general: la estructura estar-en-el-mundo engloba en sí la relación de la existencia con el ser en total; una relación comprensiva del sentido del ser en general ${ }^{2}$. La estructura del ente definido como Dasein es la aproximación originaria hacia el horizonte del sentido del Ser, hallando en su constitución mundana la proyección ontológica general. Luego, la respuesta a la pregunta fundamental del tratado está en concordancia con un modo originario de la temporeidad misma, la que se define constitutivamente en su carácter de extática.

En un nivel existencial, la existencia del Dasein inmediatamente inserta en el mundo implica una relación de aperturidad esencial que lo define como su ahí: en cuanto estar-en es su Ahí, ex-siste (fuera de sí). Tres son los elementos que determinan dicha apertura: la disposición

${ }^{2}$ La acotación directa de esta afirmación está formulada en la cita del Hüttenexemplar del § 4, Ibíd, p. 35. 
afectiva, el comprender, y el discurso, siendo este último el que los articula significativamente y de manera cooriginaria (cf. Heidegger 157-158). El comprender es el modo de su poder-ser y en el modo de su posibilidad; la disposición afectiva abre al Dasein en su condición de arrojado; el discurso articula en significaciones la comprensibilidad afectivamente dispuesta del estar-en-el-mundo.

Pero el estar-en-el-mundo se define como una estructura originaria y constantemente total (Heidegger 203), y se requiere poner de relieve el ser del Dasein para mostrar la esencial cooriginariedad de las estructuras expuestas, es decir, de un fenómeno originariamente unitario que permita que los transparente. Tal disposición afectiva comprensora que satisface estas exigencias es la «angustia». La angustia aísla al Dasein y lo abre en su ser-posible como lo que él puede ser únicamente desde sí mismo (cf. Id. 210), presentando el fundamento fenoménico para la captación explícita de la totalidad originaria de su ser revelado como cuidado: la estructura original y siempre total del estar-en-el-mundo apunta a descubrir el ser del Dasein como «cuidado» (cf. Id. 65), cuya estructura queda definida del siguiente modo: anticiparse-a-sí-estando-ya-en-(el-mundo-) en-medio-de (el ente que comparece dentro del mundo) (cf. Id. 214).

Ahora bien, luego de esta caracterización fenoménica del funcionamiento estructural del Dasein, queda pendiente su sentido. Se requiere asegurar la constitución ontológico-existencial más originaria del Dasein, es decir exponer al Dasein como un todo. Dicho de otra manera, si en el fenómeno del cuidado está contenido el ser del Dasein y en él ha quedado expuesta la constitución concreta de su ser a partir de su existencia, el análisis apuntará hacia un nivel fundamental e integral para analizar dicha constitución (Heidegger 251). Es por eso que la segunda sección se hace cargo de exponer directamente la relación fundamental del tiempo con el Dasein.

De este modo se comienza delimitando el fenómeno de la muerte (cf. Heidegger 258) en su estructura ontológica estar-vuelto-haciala-muerte. La importancia de este fenómeno es que permite una aclaración existencial del estar vuelto hacia el fin, otorgando la base suficiente para dar cuenta de la integridad del Dasein (Id. 266), donde 
su posibilidad más propia consiste en su límite más radical, referido a ninguna otra cosa que a sí mismo en el aislamiento de la angustia y sobrecogido desde su estructura unitaria como poder-ser de manera total: no referido a otra cosa que a la finitud de su ser. La inminencia de la muerte garantiza el tiempo propio y de autenticidad existencial, no porque el Dasein deba correr tras la muerte ni porque ella corra detrás suyo, sino porque su propio tiempo debe conformarse a esta estructura proyectante. De esta forma, la muerte es el fenómeno que vendría a revelar el carácter más estricto de la existencia en cuanto poder-ser.

Pues bien, la Temporeidad como sentido del Dasein llega a hacerse visible cuando se logra mostrar la conciencia de la muerte como garantía de la (finitud de la) existencia, con lo que "se pueda tener una interpretación de la estructura completa del ser del Dasein" (Heidegger 135). Al aparecer el fenómeno de la conciencia (Gewissen), la muerte es anticipada como prueba del ser total. La conciencia, entendida como llamada a ser-para-la-muerte, se comprende en íntima conexión con ella de una manera indisoluble y plena, mostrando sus fundamentos ontológico-existenciales y expresando la completitud del Dasein que es cuidado, es decir, la "llamada de la conciencia, es decir, ésta misma, tiene su posibilidad ontológica en el hecho de que el Dasein, en el fondo de su ser, es cuidado" (Id. 297).

Así, la conciencia irrumpe en un estar ya en el mundo y en una situación determinada, colocando frente al Dasein una posibilidad irrenunciable donde opta por el poder-ser, reconociendo la finitud de la muerte como delimitación de la propia existencia". Esta opción límite es la resolución, la cual de manera precursora define la finitud del Dasein y permite acceder fenomenológicamente a su sentido fundamentalmente tempóreo, desde el cual se radicaliza la visión del estar-en-el-mundo (Heidegger 367).

Contrario a la idea de que el futuro es algo que 'todavía no ha llegado', donde el pasado es algo que 'ya ha desaparecido' y el presente 'es actual', las dimensiones del tiempo originario pasan a ser determinadas desde el estar vuelto hacia el fin, esto es, desde una relación extática que manifiesta esta primacía del futuro que prontamente se empieza 
a notar en las páginas de Ser y Tiempo. Se trata de un estar fuera de sí de manera unitaria, que reordena cooriginariamente el futuro-pasadopresente como tensión o dislocación extática fundante del cuidado:

"La temporeidad se temporiza enteramente en cada éxtasis, y esto quiere decir que la unidad extática de la correspondiente plena temporización de la temporeidad funda la integridad del todo estructural constituido por la existencia, la facticidad y la caída, esto es, la unidad de la estructura del cuidado" (Heidegger 366).

Efectivamente, el Dasein no está en el tiempo, pues no es una cosa o un ente, sino que su unidad es la de su temporeidad: el sentido del cuidado como existencia es la temporeidad entendida como unidad de los éxtasis. El fundamento unitario de su posibilidad existencial es el éxtasis temporal que funciona como iluminación configuradora de su Ahí: "La temporeidad extática ilumina originariamente el Ahí como regulador primario de la posible unidad de todas las estructuras existenciales que conforman la esencia del Dasein" (Heidegger 367).

Si la regla existencial del ente que formula tal pregunta es este reordenamiento temporal que hace Heidegger, esa misma estructura es la que proyecta la ontología general. A partir de la tendencia intrínseca del tiempo aquí expresado apreciaremos la estructura extática de base con su específica tendencia prospectiva y su constitución esquemático-horizontal.

\section{La transformación heideggeriana de la doctrina del esquematismo}

La estructura estar-en-el-mundo, determinada en su ser unitario como cuidado y en su sentido ontológico como temporeidad, revela el modo de apertura comprensiva que estructura el mundo como ámbito de remisiones significativas. El tiempo cumple un papel específico en relación a la constitución del mundo, que es también constitución del mismo Dasein: "En la medida en que el Dasein se temporiza hay [o es] también un mundo" (Heidegger 381). El mundo como fondo de 
proyección del Dasein está co-abierto desde la aperturidad del Ahí, que funda el horizonte de su ser proyectante. El horizonte es parte de la unidad extática, la cual a su vez es la condición tempóreo-existencial para la posibilidad del mundo. Es en esta dinámica que es posible un mundo en unidad con el Dasein, es decir, que éste exista en-elmundo. Específicamente, es la apertura extático-horizontal la que en última instancia hace posible el mundo en su unidad con el Dasein; la unidad mundo-Dasein viene gatillada desde la unidad extática de la temporeidad proyectada de manera esquemático-horizontal. Antes de dar cuenta de ello, pondremos de relieve el trasfondo de la doctrina del esquematismo trascendental, transformada por Heidegger en esquematismo ontológico.

Digamos que para Kant, los esquemas son "determinaciones del tiempo realizadas a priori" (Kant 187) en conformidad con las categorías del entendimiento y referidas a la totalidad óntica (objetos posibles). Son elementos mediadores que refieren a los aspectos temporales de serie, contenidos, orden y conjunto, realizados por medio de la síntesis trascendental de la imaginación como determinación del tiempo. Los esquemas son la estructura que temporaliza y abre el conocimiento del mundo para que éste no se quede en una especie de 'solipsismo cognitivo', donde las categorías puras del entendimiento se reducen a simples funciones relativas a conceptos pero no remiten objetivamente a mundo. El esquema es por eso una representación mediadora pura: intelectual por un lado, y sensible por otro; es homogénea con los fenómenos y con las categorías, pero ante todo está fundado en la intuición del tiempo.

La interpretación de Heidegger busca ir más allá del tiempo como mera condición formal de la diversidad del sentido interno y de la conexión de todas las representaciones. Esta reformulación se podría graficar como una inversión de la frase kantiana "en relación con los fenómenos y la mera forma de estos, el esquematismo constituye un arte oculto en lo profundo del alma humana" (Kant 185), lo que leído heideggerianamente sería: «en relación al mero entendimiento, el esquematismo fenomenológico constituye un saber ontológico aún por desvelar». Los fenómenos corresponderían a la dimensión 
donde se teje el entramado ontológico del mundo, y los éxtasis, en cuanto sentido unitario de la temporeidad, posibilitan la existencia o la articulación existencial del mundo. Aquí emerge el punto de distanciamiento ontológico con la teoría kantiana. Ahora, en tanto tempóreo-extático, el esquema es un esquema-horizontal: se trata de un "aspecto puro" que determina al horizonte en cuanto 'hacia qué' del éxtasis correspondiente (cf. Heidegger 380).

\section{La estructura extático-horizontal de la temporalidad}

La dinámica que define al Dasein desde su constitución mundana está fundada en el tiempo. Dicho más específicamente: el tiempo está en la base de la estructura misma del cuidado, que como hemos dicho, ha quedado definida como "un anticiparse-a-sí-estando-ya-en-el-(elmundo-) en-medio-de (el ente que comparece dentro del mundo)" (cf. Heidegger 214). Si la unidad originaria de esta estructura es la temporeidad, en este punto debe surgir la comprensión del tiempo originario explicitado en la formación de los éxtasis temporales, los que corresponden principalmente a los fenómenos de futuro, habersido y presente, momentos donde literalmente y de forma temporal el Dasein sale fuera de sí:

"Futuro, haber-sido, presente, muestran los caracteres fenoménicos del "hacia- sí" ["Auf-sich-zu"], del "de-vueltaa" ["Zurück auf'] y del "hacer-comparecer-algo" ["Begegnenlassen von"]. Los fenómenos del "hacia...", del "a...", del "en medio de..." manifiestan la temporeidad como lo

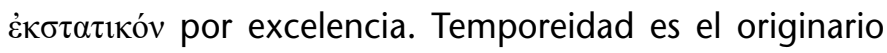
'fuera de sí', en y por sí mismo. Por eso, a los fenómenos de futuro, haber-sido y presente ya caracterizados los llamamos éxtasis de la temporeidad. La temporeidad no es primero un ente que, luego, sale de sí, sino que su esencia es la temporización en la unidad de los éxtasis" (cf. Heidegger 346).

La estructura del cuidado o ser del Dasein es interpretada extáticamente conforme al poder ser-entero que se logra desde el más propio y eminente poder-ser, haber-sido y comparecer con el mundo circundante, 
síntesis lograda en la resolución precursora y su característica eminentemente venidera (cf. Heidegger 343). Allí cada éxtasis tiene su lugar y su función unitaria. El 'antes' y el 'anticiparse' indican la posibilidad de que el Dasein se proyecte conforme a su poder-ser, fundando el futuro como sentido primario de la existencialidad; el futuro se destaca por cuanto en su poder-ser manifiesta la posibilidad de la total imposibilidad, permitiendo el comprender existentivo resuelto de la nihilidad (cf. Id. 347). El 'ya' refiere al sentido existencial y tempóreo del ser que, en cuanto es, está siempre arrojado, lo que es posible en el haber-sido fundante. En otras palabras, el Dasein no deja de ser un ente que ya es, reencontrado a sí mismo desde su condición de arrojado. El tercer momento, el ('cadente' y 'ocupado') estar-en-medio-de, se funda en la presentación, la cual queda incluida en el futuro y en el haber-sido (cf. Id. 344-345). Ella representa el estar en medio del mundo, vuelto principalmente sobre las ocupaciones ónticas que lo definen cadentemente. Así, los tres momentos son recapturados extáticamente en la finitud propia y en su sentido unitario, establecidos a partir de la estructura del cuidado. El mundo se constituye desde esta existencia resuelta, la cual es posible en los éxtasis temporales que permiten el desdoblamiento transversal a la unidad total del tiempo enfocado hacia su propia finitud. Los éxtasis se manifiestan así como el sentido trascendente hacia la dimensión más originaria de las estructuras del Dasein que fueron definidas como comprensión, disposición afectiva y discurso. De esta manera la unidad de la temporeidad extática se ha mostrado en la estructura formal del cuidado: anticiparse-a-sí-estandoya-en-(el-mundo) en-medio-de (el ente que comparece dentro del mundo (cf. Id. 314), expresada como totalidad originaria en la unidad «existencia, facticidad y caída», manifestando una radicalización tempórea en el nivel más originario.

El tiempo se temporiza de acuerdo y conforme al horizonte de proyección que posibilita la existencia del mundo, por eso puede decirse que el mundo existe co-extensivamente en el 'fuera de sí' de los éxtasis (Heidegger 381). De acuerdo a esto, a cada éxtasis le corresponde un esquema horizontal $u$ horizonte esquematizado que prefigura el 'hacia qué' de las salidas de sí mismo. Específicamente, el esquema que prefigura al horizonte del advenir, propio o impropio, es el por-mor-de 
sí; el esquema del horizonte del haber sido es el ante-qué de la condición de arrojado o, correlativamente, el a-qué del estar entregado; y el esquema horizontal del presente se determina por medio del paraalgo. En el horizonte del futuro queda proyectado un poder-ser; en el horizonte del haber-sido queda abierto el 'ser $y a^{\prime}$; y en el horizonte del presente queda abierto el objeto de ocupación (cf. Id. 380). La unidad horizontal de los éxtasis hace posible la apertura del mundo del Ahí proyectado comprensivamente en su hacia-qué, fundamento del horizonte de comprensión ontológica y constitución del mundo.

\section{El pasaje desde la Analítica del Dasein hacia el desarrollo de la cuestión ontológico-general: Temporeidad y Temporariedad}

De acuerdo al hilo programático de Ser y Tiempo, la investigación comienza planteando la pregunta por el sentido del ser sin más; se despliega hacia el estudio de la estructura del Dasein (Analítica del Dasein) y luego debiera retornar hacia la pregunta ontológico-general. Aproximémonos a este último paso teniendo claro que la obra se interrumpe al finalizar la Segunda Sección y no desarrolla sistemáticamente la tesis central. Aun cuando las menciones del escrito resultan de mucha importancia para entender el propósito y el camino que debe seguir el programa, disponemos además de una fuente posterior que permitirá una comprensión más acabada de la cuestión ontológicogeneral, tema de la Tercera Sección «Tiempo y Ser»; nos referimos a la lección Los problemas fundamentales de la Fenomenología.

En cierto modo ya hemos hecho referencia al modo en que el tiempo cumple su rol sistemático de abrir el horizonte ontológico general, en concordancia con el objetivo programático. Ahora bien, el momento final de la Sección Segunda (parágrafo 83) anuncia la tarea posterior de explicitar el horizonte temporal del ser en general. Se recuerda aquí que los resultados de la investigación en sus dos primeras secciones han consistido en la interpretación del todo originaria del Dasein en la perspectiva del existir propio e impropio, cuyo fundamento se reveló en la temporeidad. Sin embargo, a la luz de la meta del Tratado, este 
análisis sigue siendo tan sólo un camino, el cual debe seguir aclarando la pregunta ontológica fundamental. Aún la misma analítica de la existencia necesita de la luz que viene de la previa aclaración de la idea del ser en general.

Dentro de las Lecciones, Heidegger retoma claramente la temática del tiempo horizontal, inconclusa desde la Sección Segunda, recordando que la Temporeidad se ha descubierto como sentido del ser del Dasein, donde radica su comprensión del ser, la cual sólo es posible sobre la base de la temporalidad. Desde este punto se abre nuevamente el problema ontológico general del tiempo como sentido del ser:

"(...) la perspectiva de una posible demostración de la tesis de que el tiempo es el horizonte a partir del cual se hace comprensible algo así como el ser. Interpretamos el ser a partir del tiempo (tempus). La interpretación es temporánea [temporale]" (Heidegger, Los problemas fundamentales de la fenomenología 42).

Se reafirma de este modo la específica temporalidad que permite la apertura del ser en general, la que trasciende la temporeidad: "La problemática fundamental de la ontología como la determinación del sentido del ser a partir el tiempo es la temporaneidad [Temporalität]" (Ibid), que hemos usado aquí como temporariedad. La función del estudio de la temporariedad quiere indicar la remisión intrínseca del sentido del Dasein a la constitución ontológica general (cf. ld. 278279). En conexión con la Segunda Sección, la Tercera Sección vendría a corroborar esta relación entre la temporeidad extática, punto de arranque de la explicitación originaria del tiempo en cuanto horizonte del ser (Von Herrmann 42), y el proyecto extático fundado en la temporeidad. Este paso está generado desde la dinámica de formación de sentido (Sinnbildung), propia del Dasein, a la cual Heidegger suele caracterizar como "trascendencia" (cf. Heidegger, Los problemas fundamentales de la fenomenología 352-360).

Es en la constitución fundamental del ser-en-el-mundo donde se muestra el modo originario de la trascendencia, puesto que trascendiendo, el Dasein se dirige al mundo en cuanto ente, sea subsistente, sea el otro 
o sí mismo. Tal movimiento representa el fundamento de la comprensión previa del ser, la cual, "en su totalidad específica, se fundamenta en la unidad extático-horizontal originaria de la temporalidad" (Id. 360). La apertura constitutiva del mundo que se configura en el esquematismo horizontal de la temporeidad extática constituye el horizonte desde el cual es posible articular la cuestión ontológico-general. La temporalidad tomada de esta forma, "primariamente con relación a los esquemas horizontales de la temporalidad como condiciones de posibilidad de la comprensión del ser, constituye el contenido del concepto general de la temporaneidad" (Id. 366), concepto que, de acuerdo a la dinámica extático-horizontal, no deja de estructurarse en un sentido marcadamente prospectivo.

\section{Consideraciones en torno a la tendencia prospectiva del tiempo}

Los desarrollos llevados a cabo por Heidegger han sido explicitados como una investigación acerca de la constitución extático-horizontal del Dasein, con vistas a explicitar al tiempo como sentido general del ser. El reordenamiento de las tres dimensiones temporales de presente, pasado y futuro es central en este desvelamiento programático. Según tal reordenamiento, la temporeidad se temporiza primariamente como futuro presentante que está-siendo-sido. De este modo, la temporeidad del Dasein, en vistas a la cuestión ontológico-general, ofrece el horizonte para la comprensión del ser (temporariedad).

Si la tarea general de Ser y Tiempo ha sido revelar el tiempo como horizonte de la comprensión del ser, la temporariedad ha tenido que ser explicada originariamente a partir de la temporeidad como ya lo hemos expresado. Aquí resulta sugerente observar cómo Heidegger asume la exigencia de acotar el análisis frente a la concepción vulgar del tiempo (Heidegger, Ser y Tiempo 41-42), distinción que tiene su base en la reformulación del tiempo en tanto futuro-pasado-presente.

Por lo mismo, entiende la interpretación vulgar del tiempo como el encubrimiento de los caracteres tempóreos esenciales de la ocu- 
pación circunspectiva, a saber, el encubrimiento del tiempo de la ocupación en su databilidad (el ahora datable que se comprende en el ocuparse y que es siempre un ahora apropiado o inapropiado) y la significatividad o relación de cada momento con una acción posible (el tiempo para...) (cf. Id. 436). Estos caracteres son posibles en la aperturidad del mundo, la cual pone al descubierto el ente intramundano y hace público al tiempo, siendo aquí donde "el tiempo se ha vuelto siempre objeto de ocupación" (Ibid), una ocupación calculadora del tiempo que remite al seguimiento presentante y numerante del uso del reloj, presentación temporizada "en la unidad extática con el retener y el estar a la espera horizontalmente abiertos según lo anterior y lo posterior" (Id. 435), noción que corresponde en última instancia a Aristóteles.

Pues bien, cuando el tiempo del mundo, desde su tendencia presentante y cadente "se muestra como una serie de ahoras constantemente "presentes" a la vez que transcurrentes y advenientes" (Id. 436), desviándose de la determinación e indicación del tiempo como tal, acaece el encubrimiento generado por la interpretación vulgar del tiempo, en la que se diluyen o nivelan dicha databilidad y significatividad (además de su mundaneidad, tensidad y publicidad existencial). En síntesis, no se dispone entonces de un horizonte que permita hacer accesible el mundo en cuanto tal. Aún en la Lección de 1927 se deja claro que la trascendencia extático-horizontal consiste en una proyección hacia el mundo, es decir, sólo se comprende el ser en la medida en que es proyectado hacia un horizonte (Id. Los problemas 336), apareciendo este como el espacio de relación significativa con lo intramundano. Con esto surge el problema de la configuración de otros mundos, vale decir, la constitución de otras épocas y culturas.

Respecto a ello, podríamos advertir en el planteamiento heideggeriano las consecuencias de la tendencia prospectiva y horizontal. Se aprecia el desafío de elaborar una comprensión del tiempo que integre la referencia trascendente que marca el proyectar lineal -donde el pasado confirma el curso progresivo del tiempo-, e incorpore a su vez la referencia inmanente al retroproyectar y su vínculo intrínseco más intenso con el pasado datable y significativo. Desde este punto pode- 
mos cuestionar el énfasis heideggeriano en la relación primariamente anticipatoria y proyectiva de los éxtasis con su horizonte, planteando la posibilidad de otra primacía temporal, como podría ser la de un movimiento retroproyectivo.

El cuestionamiento al énfasis anticipatorio heideggeriano se puede formular del siguiente modo: ¿cómo la temporeidad extático-horizontal lograría explicar la constitución ontológica desde la que proyecte otra época, específicamente una fundada no en una visión prospectiva sino retrospectiva? El planteo que está en la base de nuestro cuestionamiento es el siguiente: la relación con el pasado expresa el elemento lineal en perspectivas de un futuro $y$, a su vez, recoge un elemento circular en perspectivas del pasado en sí. El esquemático hacia-qué implica una cierta rigidez a la hora de abrir la posibilidad de otro tipo de preeminencia, como por ejemplo la de un desde-dónde.

Consideremos aquí el fenómeno de la tradición. En Heidegger, este aparece ligado al tiempo vulgar y al encubrimiento de las fuentes originarias, acarreando junto con ello el desarraigo de la historicidad del Dasein. La doctrina del tiempo en Heidegger se funda sobre la crítica fundamental al modo en que la tradición filosófica ha comprendido el ser. A su juicio, la ontología tradicional desarrolla una comprensión del tiempo que se centra principalmente en el presente. De esta forma, la crítica a la tradición es la base del replanteamiento propuesto por Heidegger. Pero, ¿hasta qué punto es pertinente esta crítica destructiva al modo de entender el movimiento tempóreo de la tradición?

La tradición es un fenómeno eminentemente tempóreo que comprende la dimensión de pasado, presente y futuro, pero que enfatiza de modo especial el pasado. Se define como el traspaso o transmisión de elementos desde un punto anterior en el tiempo hacia la interpretación presente, en una dinámica de conservación que permite la continuidad mediante la recuperación histórica de dichos elementos. Implica la conexión del evento del pasado con el presente y la proyección hacia un futuro que hereda lo esencial del acontecimiento, el cual se recupera y conserva en tanto 'tradicional'. Esta dinámica estructura el tiempo sobre la base de una relación tri- 
partita, cuya característica primordial es la institución de momentos perdurables y recuperables. El concepto de tradición se ve integrado más profundamente cuando lo percibimos en su sentido circular, de repetición o reactualización del pasado. De alguna forma comprende una circularidad conectada con un cierto sentido lineal, pues en la recepción presente del elemento pasado se re-crea un movimiento que proyecta el tiempo prospectivamente.

Ahora bien, no olvidemos que Heidegger logra inferir una comprensión de la tradición en conformidad con su doctrina del tiempo. Efectivamente, da cuenta de una reelaboración del concepto de tradición, según la cual consiste en la dinámica temporal que entrega posibilidades asumidas en tanto legado recogido en el retorno resuelto a la condición de arrojado. Constituye la herencia o el legado que el Dasein asume en tanto arrojado, lo que permite la apertura de las posibilidades fácticas en el existir propio de la resolución. En este sentido, la repetición "es la tradición explícita, es decir, el retorno a posibilidades del Dasein que ha existido" (Id. 401). A nuestro juicio, se trata aquí de un sentido de tradición recogido desde la in-diferencia del instante, en el cual la repetición ni se abandona al pasado ni aspira a un progreso: sólo un ente esencialmente venidero en su ser puede -entregándose a sí mismo la posibilidad heredada- asumir la propia condición de arrojado y ser para 'su tiempo' en el instante.

Para Heidegger, la tradición en cuanto base de replanteamiento ontológico del tiempo se comprende como un elemento que se aparta del horizonte de una comprensión ontológica general, encubriendo y endureciendo el sentido del ser, alejándose de una posible proyección retroactiva. Se advierte una tensión entre una manera de entender la tradición como repetición para un tiempo propio y la concepción crítica de la tradición filosófica, concepción que está en la base del método de la "destrucción". Esto nos conduce a preguntar si acaso se requiere inevitablemente de una radical destrucción para lograr establecer la apertura ontológica general, es decir, si es necesario desmontar los presupuestos de una tradición que no mostraría el carácter fundante del tiempo en cuanto tal y elude su sentido plenamente 
auténtico, el cual se hace accesible no en el marco del desmontaje estricto, sino, por ejemplo, en una operación dialogal basada en la lógica de la pregunta y la respuesta ${ }^{3}$.

\section{Conclusión}

Desde la tendencia prospectiva y horizontal que caracteriza el tiempo en Heidegger, planteamos la cuestión en torno a una legítima propiedad ontológica de otros sentidos fundantes del tiempo. En esta línea emerge el problema de la tradición como fenómeno tempóreo que manifiesta su sentido auténtico en la profundización unitaria del pasado con el presente y el futuro. Más que como obstáculo, la tradición se ha mostrado como un proceso que interviene en la constitución de la totalidad tempórea del estar en el mundo, lo que podría plantearse como resolución retro-proyectiva.

Sin embargo, Heidegger clausura la posibilidad de pensar la constitución ontológica general desde otra primacía tempórea de trascendencia constitutiva del ser en general, como la primacía del pasado en la tradición. Con ello no permite entender cómo es posible la pluralidad de mundos concatenados, experiencia histórica básica. Aun cuando reelabora el concepto de tradición bajo las nociones de herencia y legado, manifestados en las posibilidades asumidas desde el retorno resuelto a la condición de arrojado, los análisis no lograrían hacer justicia al dinamismo retro-proyectivo de la tradición como experiencia historizante y a la peculiar linealidad que esta conlleva, lo que asimismo daría pie al surgimiento de nuevas cuestiones relacionadas a una visión más precisa en torno al sentido ontológico general del tiempo.

3 En este sentido, ha sido Gadamer quien ha aportado indicaciones interesantes. Gadamer, Hans-George, Verdad y Método I, Ediciones Sígueme, Salamanca, 1999, pp. 344-377 y 461-486. 


\section{Bibliografía Citada}

Heidegger, M. Los Problemas Fundamentales de la Fenomenología. Madrid: Editorial Trotta. 2000b.

Heidegger, M. Ser y Tiempo. 3ª ed. Santiago: Editorial Universitaria. 2002.

Kant, E. Crítica de la Razón Pura. 6ª ed. Madrid: Ediciones Alfaguara. 1988.

Rubio, Roberto Gustavo. Tiempo y sentido. Sobre la recepción de Heidegger del esquematismo trascendental kantiano en el periodo de "Ser y Tiempo". Revista Praxis Filosófica Nueva Serie (19): 5-21. 2005.

Von Hermann, Friedrich-Wilhelm. La "Segunda Mitad" de Ser y Tiempo. Sobre los problemas Fundamentales de la Fenomenología de Heidegger. Madrid: Editorial Trotta. 1997.

\section{Bibliografía Consultada}

Escudero Pérez, Alejandro. Ser y Tiempo: una obra interrumpida. Revista de Filosofía Eikasia (41): 133-150. 2011.

Gadamer, Hans-George. Verdad y Método I. 8va. ed. Salamanca: Ediciones Sígueme. 1999.

Gadamer, Hans-George. Los Caminos de Heidegger. 2a. ed. Barcelona: Ed. Herder, 2002.

Leyte, Arturo. Heidegger. Madrid: Alianza Editorial. 2005.

Pöggeler, Otto. El camino del pensar de Martín Heidegger. 2a. ed. Madrid: Alianza Editorial. 1986. 